\title{
Transparency, Accountability and Participation through Social Audit: Case of MGNREGA in Sikkim, India
}

\author{
Feba Varghese $^{1}$, N C Narayanan ${ }^{2}$, S B Agnihotri ${ }^{3}$, Girija Godbole ${ }^{4}$ \\ ${ }^{I}$ Research fellow with Centre for Technology Alternatives in Rural Areas (CTARA), \\ IIT Bombay and Ministry of Rural Development, NewDelhi,feba31@gmail.com \\ ${ }^{2}$ Professor with Centre for Technology Alternatives in Rural Areas (CTARA), IIT Bombay, ncniit@gmail.com \\ ${ }^{3}$ Professor with Centre for Technology Alternatives in Rural Areas (CTARA), IIT Bombay, sbagnihotri@iitb.ac.in \\ ${ }^{4}$ Post-doc fellow with Centre for Policy Studies, IIT Bombay, GIRIJAG@gmail.com
}

\begin{abstract}
Transparency, accountability and participation (TAP) are some essential elements for ensuring democratic governance. Social audit is an operational instrument to reduce corruption by empowering people to scrutinize public expenses, detect corruption, and ensure accountability. Social audit is one of the robust element of MGNREGS (Mahatma Gandhi National Rural Employment Guarantee Scheme) in India as they work through the Panchayat, and stimulate the public to participate with a sense of communal accountability. At the state level even five years after the issue of operational guidelines, we witness wide variations in the quality of social audits. Different states have adopted their own models and while some of them are successful, some of the states have still not set up and some are in the process of setting up an independent social audit unit. The Non-Governmental Organization (NGO) model of social audit in the state of Sikkim which is not widely discussed in literature is the focus of the study. This research attempts to study the efficacy of Social audit as a tool to bring Transparency, Accountability and Participation in MGNREGA taking the case of Sikkim.
\end{abstract}

KEYWORDS: Transparency, Accountability, Participation, Social Audit, MGNREGA, Development, Public Policy

\section{Introduction}

Social audit is a tool in democratic governance where the concerned group claims the right to information and verification from implementing agencies in an organized manner, thus leading to public accountability (Aakella \& Kidambi 2007), transparency and participation. It is a tool for empowerment of the stakeholders by an independent body not belonging to the parent institution (Aiyer \& Samji 2009). The social audit process involves a participatory approach from the beneficiaries (people who have received the benefit from the scheme) to ensure better transparency, accountability and participation.

With more that 110 million active workers, Mahatma Gandhi National Rural Employment Guarantee Scheme (MGNREGS) is one of the world's largest social security schemes in the world guaranteeing 100 days of unskilled manual work to all rural households in India. In the year 2018-19, MGNREGS generated 2.67 billion person days reaching 52.6 million households in rural India. Taking into consideration, the large span of region it has to cover, tracking the massive volume of benefit it offers is a really big task. Even though, MGNREGA has a vibrant and technically sound Management Information System (MIS) to monitor the different tasks and implementation status of the department, the field experience shows that it doesn't always comply with the ground truths and the need to go for a participatory approach is quite real on ground.

The MGNREGS guidelines mandates the necessity to encourage public's participation within the audit in conjunction with assistance furnished via an independent social audit unit that enables the process (MoRD 2013). According to the recommendations of the Ministry of Rural Development (MoRD), the state governments are to establish a Social Audit Unit (SAU) that is independent from the implementing authorities. The SAU ought to be located outside the department that is executing MGNREGS and it needs to have an independent bank account. The SAU must also have a full time director who is not involved in the implementation of MGNREGS. The guidelines mandates that it is to be conducted in each Gram Panchayat (GP) as a minimum once in six months (MoRD 2013). The 
focus on this study is focused on the NGO model of social audit followed by the North-Eastern state of Sikkim, India in understanding how efficient is social audit in ensuring the elements of transparency, accountability and participation in MGNREGS.

\section{Social audit in an Indian Context}

There are various movements that have rose in the country in the context of transparency, accountability and public participation in the activities of the government and some of them are associated with a specific cause, sectoral issue and local crisis. The movement towards environment protection, farmer's movements, public interest litigation movement etc., are few examples of this movement. Most of these movements come into action on perceiving the failure of government in effectively implementing schemes and there was a need for policy interventions.

In the early 1990s, the city of Bangalore was facing issues because of sub-standard public service despite being a major service sector hub. It was observed that the municipal corporations were unreliable and an independent citizen report card exercise was conducted by a group of residents to evaluate citizen satisfaction from services in the year 1993. Successively, the group formed the Public Affairs Centre (PAC) to carry out more surveys. Literatures report that this exercise of report card helped to raise the awareness of service providers' poor performance and compelled them to take corrective measures (Thampi 2005). The report card exercise was again conducted in the years 1999 and 2003. The feedback form used assessed user satisfaction in such parts as staff behaviour, the number of visits required to complete a task, ease of resolving issues, and the quality of information delivered (Thampi 2005).

Another pioneer in conducting social audit in India is the organization named Mazdoor Kisaan Shakti Sangathan (MKSS) rooted in the state of Rajasthan. It is a well-known organization in India famed for its advocacy towards Right to Information Act and for its use of public hearings as a monitoring tool towards accountability. After procurement, data is analysed and are made public to the citizens through the process of 'Jan Sunwai' or public hearing (Goetz, A.M and Jenkins J, 1999). MKSS started conducting 'public hearings' or 'Jansunwai' to enable people to speak about the issues they were facing in various government programmes. MKSS also went to the leadership and discussed the issues with the Chief minister of Rajasthan and their first victory came with government notification of Panchayat Act that the data pertaining to Panchayat expenditure could be scrutinized by the citizens.

Rajasthan passed the Right to Information Act in 2000, an advancement made successful by the pressure of MKSS. The MKSS deduced that non-transparency and non-accountability are the primary reasons for the proliferation such widespread corruption. Until then no official records were shared with the citizens and hence no one could question or demand explanation. The right of people to know the activities of governments and how government money from citizens is being utilized thus became one of the major agenda of the MKSS. Through their accomplishments, the MKSS claimed admittance to government data related to local administration and development (Aiyer, Yamini and Salimah Samji, 2009). Obtaining official records is the first step in social audit and Right to Information Act in 2005 made this an easy process.

An important conception in this process was the 'public hearing' where details of the authorized records were read out to the assembled villagers. The local citizens who were victims of corruption were summoned to give witnesses and the officers and local politicians were given a chance to publicly shield their activities (Goetz, A.M and Jenkins J, 1999). In addition to exposure of corruption, the public hearings also play a crucial role to empower citizens and it aids in strengthening democracy. Chandoke in her study of the public hearing discusses that public hearings perform three purposes inherent to democracy which are informing citizens, encouraging public participation and creating responsibility to resolve issues of collective concern (Chandoke N. 2007). The social audit process creates a platform to spread awareness and to exercise the rights and entitlements. As per Para 6, Audit of Scheme Rules 2011, the activities that are being undertaken for facilitating the conduct of Social Audit by Gram Sabha are as shown (Table 1). 
Table 1. Activities in Social Audit

\begin{tabular}{|l|l|}
\hline \multicolumn{1}{|c|}{ Activity } & \multicolumn{1}{c|}{ Tasks Involved } \\
\hline Verification and Awareness & $\begin{array}{l}\text { Door to Door Verification, Inspection of Worksite and } \\
\text { conduct of village level awareness }\end{array}$ \\
\hline Documentation \& Reporting & $\begin{array}{l}\text { Preparation of Social Audit Report and display on the } \\
\text { notice board of the Gram Panchayat }\end{array}$ \\
\hline Public Hearing / Jan Sunwai & $\begin{array}{l}\text { Conduct of Public hearing or Jan Sunwai to share findings } \\
\text { of the verification exercise (Auditing Standards mandates } \\
\text { that all the elected members of the Panchayat and staff } \\
\text { shall be present at the Gram Sabha and respond to } \\
\text { queries). }\end{array}$ \\
\hline
\end{tabular}

\section{Initial Steps of Institutionalizing Social Audit in MGNREGA}

Andhra Pradesh is the first state in India that took steps to Institutionalize the social audit in MGNREGA. In the past, the state of Andhra Pradesh had an unpleasant record of implementing rural employment guarantee programs and there were outcries for improvement. (Deshingar, P. and Johnson, 2003). The Department of Rural Development decided to implement the social audit process as part of the Administrative Reform Action Plan. It began in 2006 as a project carried out by the Strategies Performance Innovation Unit (SPIU), Rural Development in three districts of AP. This later on led to its metamorphosis into the Society for Social Audit, Accountability and Transparency (SSAAT) carrying out regular and concurrent social audits across 22 districts. SSAAT was formally registered as an independent Society on the 15th of May, 2009. While Section 17 of MGNREGA mandates the conduct of Social Audits, no clear mechanism of how to conduct a Social Audit has been indicated in the Act or associated guidelines. The first state to make an independent effort to push for this was the Department of Rural Development, Andhra Pradesh.

After realizing the merits of the Social Audit process in Andhra Pradesh, the Government of India adopted a similar model of social audit and made it mandatory for every state to establish an independent Social Audit Unit (SAU), as per the Audit of Scheme Rules 2011, MGNREGA. Every SAU should be headed by a governing body responsible for overseeing the performance and it shall compose of Principal Accountant General, C\&AG, Principal secretary Department of Rural Development, director social audit Unit, 3 representatives from Civil Society Organization (CSO) and other special invitees from departments that are undertaking social audit programmes. It shall also be ensured the Principal Secretary, Department of Rural Development does not chair the governing body for ensuring independence. The Ministry also recommends $100 \%$ audit of beneficiaries and that social audit needs to be conducted at least once in 6 months.

\section{Focus \& Study Area}

Advancing transparency and accountability is presently generally acknowledged as a foundation of reasonable improvement. The field at present includes zones, for example, anti-corruption, right to use data, resident input and participation in administration forms, accountability inside administration conveyance, and increasing subject "voice" in broad daylight issues (Kalathil, 2016). As greater government data end up accessible to the more extensive open, common society will have more weapons to consider executors answerable, in this way lessening defilement and fortifying government authenticity. Empowerment ought to be viewed as a procedure through which poor people, barred and powerless areas of the social order are educated of their rights and qualifications, so they can take an interest and impact the governance procedure and in the long run coordinate with the standard talk (Vij, 2011). Social audit is additionally a procedure through which individuals draw in themselves in assessing the plan and their insight into their rights and privileges are upgraded. The research framework used for the study is depicted in the figure 1. The Transparency, Accountability, 
Participation (TAP) elements in social audit in MGNREGA was evaluated by studying the policy in detail along with field visit experiences as a first step.

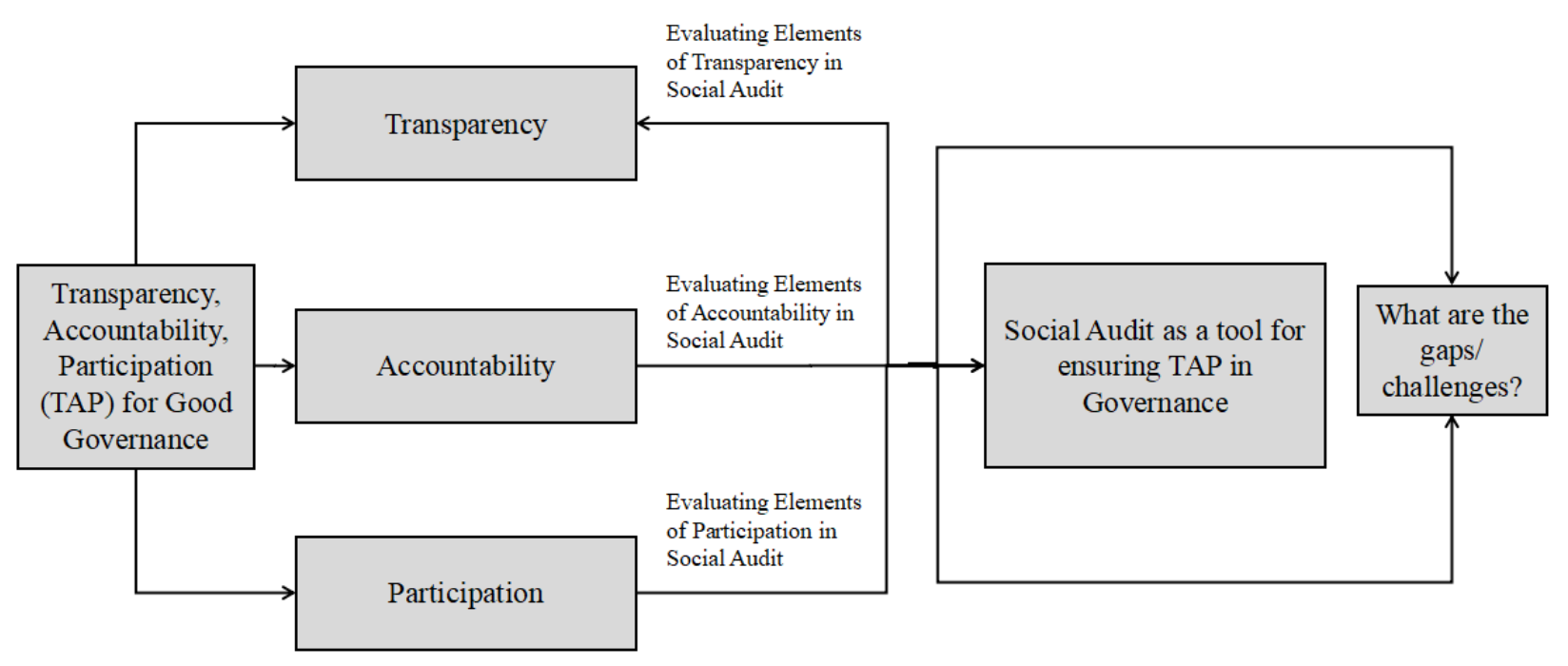

Figure 1. Framework for Analysis in the Study

The performance and quality of social audits across the states have been far from uniform and different states have adopted different models of SAU like society model, cell within implementing agencies, Non-Government Organization (NGO) model etc. In 2014, Ministry of Rural development (MoRD) evaluated that only Andhra Pradesh and Sikkim were fulfilling the requirements social audits as foreseen in the guidelines (Tambe, Subba, Basi, Pradhan, \& Rai 2016).

With this context, this paper focuses on the NGO model of social audit followed by the state of Sikkim which is not widely discussed in literature. The primary data for this research was collected from field visits to villages in Sikkim, Andhra Pradesh and Maharashtra from December 2016 to May 2018. For the research, primarily three Gram Panchayats (GP) of Sikkim were selected, Sanghanath GP from South District and Samlick Marchak and Nandok Saramsa GPs from East District. The secondary data was collected from the MGNREGA official MIS and from the social audit offices for validation purposes to deepen the understanding. Also, for quantitative analysis and mapping, secondary data from 30 GPs from different districts of Sikkim (depending on the availability) was collected from offline documents. The qualitative data was collected with the use of semi-structured, unstructured interviews and focus group discussions. The focus of this paper is on the NGO model of Sikkim owing to the fact that it isn't much discussed in the literature and a good understanding of this model will assist in replication in other states trying to establish their own Social Audit Unit.

\section{SAU Model in Sikkim}

The Rule 4 of Audit of Schemes Rules, 2011 stipulate that each state Government shall identify or establish an independent organization, Social Audit Unit (SAU) to facilitate conduct of the Social Audit of MGNREGS works. Voluntary Health Association (VHA) of Sikkim has been recognized by the Rural Management \& Development Department, Government of Sikkim as the independent organization to function as the Social Audit Unit (SAU) for conducting Social Audits of MGNREGS works in the state of Sikkim. In the case of Sikkim, it was the civil society organizations who were instrumental in institutionalizing the Social Audit Unit. VHA has been facilitating the Social Audit for East and North of over 5 years since 2008. Over this year SAU has under gone for long process in collaboration with Rural Management \& Development Department, Government of Sikkim to set up Social Audit Unit in the State. In district level there are District Resource Institutions (DRIs) for each 
district supported by District Resource Persons (DRPs) who will conduct Social Audit in their respective district.

Sikkim has developed two models of Social Audit process for MGNREGA, viz. Intensive model and Paired Model. In the Intensive model, all step wise activities would be held for the particular GP by the concerned District Resource Institutions (DRI) at a time. The DRI would complete one Gram Panchayat at a time. In Paired Model of MGNREGA, Social Audit process will remain as intensive model but the Social Audit will be conducted in two GP at a time in order to save the resources.

Full-fledged social audit began in the state from financial year 2013-14 and the same has been continued from 2014-15. The details of the number of GPs covered over consecutive years are mapped as given (Table 2, Compiled from information available from VHA, Sikkim). In the pilot audits, they could cover only $50.57 \%$ of the total GPs could be covered but from 2015, all the GPs under MGNREGA are covered by the Social Audit but 100\% coverage through house visit is not achieved. In all the districts except the East district, the social audit is further distributed to other NGOs in the respective districts under the guidance of VHA. VHA organizes training for the personnel involved from other NGOs and during field work, the DRP from VHA also accompanies them.

Table 2. Percentage Coverage of GPs by SAU over consecutive years

\begin{tabular}{|l|l|l|l|l|l|}
\hline \multirow{2}{*}{$\begin{array}{l}\text { S.L } \\
\text { No. }\end{array}$} & \multirow{2}{*}{ District } & \multicolumn{4}{|c|}{ \% Coverage of GPs by SAU } \\
\cline { 3 - 6 } & & $\mathbf{2 0 1 3 - 1 4}$ & $\mathbf{2 0 1 4 - 1 5}$ & $\mathbf{2 0 1 5 - 1 6}$ & $\mathbf{2 0 1 6 - 1 7}$ \\
\hline 1 & North District & $75 \%$ & $50 \%$ & $100 \%$ & $100 \%$ \\
\hline 2 & East District & $48 \%$ & $52 \%$ & $100 \%$ & $100 \%$ \\
\hline 3 & South District & $44 \%$ & $53 \%$ & $100 \%$ & $100 \%$ \\
\hline 4 & West District & $47 \%$ & $52.73 \%$ & $100 \%$ & $100 \%$ \\
\hline \multicolumn{2}{|c|}{ Total } & $50.57 \%$ & $52.27 \%$ & $100 \%$ & $100 \%$ \\
\hline
\end{tabular}

\section{Transparency through Social Audit}

Transparency basically includes the components of information, accessibility and usability. Data transparency portrays a condition in which residents approach the information and reports that bear upon moves and choices made by government on-screen characters (Harrison \& Sayogo, 2014). The privilege of individuals to comprehend what their governments are doing and how government reserves are being used in this manner is the key element of transparency being insured through social audit in MGNREGA.

Getting official records is the initial phase in social audit and Right to Information Act in 2005 made this a simple process. One of the critical command in the policy is that the Programming Officer should make the required data accessible with the social audit groups 15 days before the initiation of Social Audit. The GP officials should ensure that all the pertinent records, including complete documents of the works or duplicates of them, ought to be made accessible for review at the Gram Panchayat office no less than 15 days ahead of time of the Social Audit Forum. There ought to be free and simple access to these reports for all inhabitants of the Gram Panchayat amid this period, and no expenses ought to be charged for examination. The first records ought to be accessible upon the arrival of the Forum, with the goal that any document can be verified.

Along these lines, the kind of transparency that existed prior to the establishment of Social Audit was reactive transparency and through the establishment of Right to Information Act, there was a request to move to pro-active transparency. Earlier, the poor beneficiaries of MGNREGA didn't have any mechanism to know or understand how the fund is being utilized by the officials and the social audit has opened their eyes to this issue. During our interaction one of the mate (Mate is a work-site supervisor. At least one mate should be present for every 100 workers.) commented saying, "If social audit didn't exist these people would have come accused us of misusing/ withholding their money. Because of the audit these people have more faith in us since all things are transparent to them". The Gram Sabha is supposed to discuss findings of the social audit through 'Public Hearing' and this is a 
step towards enhancing the transparency of information. It was observed during the house visit that some were curious as to why the social audit people were collecting the information and the officials had to softly explain to them the purpose and need for audits.

Analysis of available information show that from 2013 to 2017 as shown (Table 3, Compiled from information available at VHA, Sikkim). This could be a reason of more misappropriations or as a result of people being more vocal about their issues. Semi structured interview revealed that the cases of financial misappropriation were high in the initial years but at present more cases of process violation are being reported. In social audit in MGNREGA of Sikkim, the steps towards transparency were mainly through Pro-active disclosures, meticulous documentation and through discussions in Public Hearing.

Table 3. Number of Issues Reported in Social Audit

\begin{tabular}{|c|c|c|c|c|c|c|}
\hline \multirow[b]{2}{*}{ S.L No. } & \multirow[b]{2}{*}{ District } & \multirow[b]{2}{*}{ Total GPs } & \multicolumn{4}{|c|}{ Number of Issues Reported } \\
\hline & & & $2013-14$ & 2014-15 & $2015-16$ & $2016-17$ \\
\hline 1 & North District & 24 & 573 & 121 & 281 & 278 \\
\hline 2 & East District & 50 & 364 & 374 & 702 & 507 \\
\hline 3 & South District & 47 & 235 & 194 & 392 & 381 \\
\hline 4 & West District & 55 & 309 & 364 & 1110 & 997 \\
\hline \multicolumn{2}{|c|}{ Total } & 176 & 1481 & 1053 & 2485 & 2163 \\
\hline
\end{tabular}

Proper documentation is an essential element to ensure good transparency of the scheme. All the MGNREGA documents are to be properly verified during the Document verification phase in Sikkim through systematized formats and the findings are meticulously documented as booklets for future use. The Gram Panchayat personnel are instructed to make available all relevant documents available to the Gram Sabha for the purpose of facilitating the social audit. The audit of Scheme Rules recommends the entire proceeding of the Social Audit Gram Sabha to be video recorded and uploaded on website without editing which is also a step towards more transparency. However at present, this is not being done as the computer system server doesn't have enough to space to accommodate the large video files.

Through social audit in MGNREGA, many pro-active disclosures have made things more transparent to the people. To ensure transparency, calendar uploading is done prior to audit but field level experience often showed that if the mates knew when the visit is going to take place, they would try to set things right for the day of audit. Prior to the Jan Sunwai, announcements are made through microphone in the village and posters are pasted in important places to inform the public about the audit but in the hilly terrain with less dense population, it is harder than plain areas to inform the public. During the public hearing, all the findings made in the audit process is displayed in the form of charts to make the information more understandable to the people. The minutes of the Public Hearing is also supposed to be displayed on the notice board of Gram Panchayat in the local language according to the policy and it was observed to be followed.

\section{Participation through Social Audit}

The involvement of citizens in the political process is an essential part of democracy. Inclusiveness is also an important element along with the consideration in basic leadership of those most influenced by the proposed decisions. At its most impenetrable, support in a social occasion is described similar to nominal participation (Molinas 1998) and at its broadest to an extent in which even the vulnerable have voice and effect in essential authority (White 1996). The types of participation as given by literature are (Agarwal 2001):

i. Nominal participation: People have membership in the group

ii. Passive Participation: Participants are aware of choices ex post facto; go to gatherings and listen but do not voice their opinions

iii. Consultative Participation: Participants are asked opinions in specific matters but there is no assurance their opinion will influence the decisions 
iv. Activity-specific Participation: Participants are asked to volunteer for certain tasks alone v. Active Participation: Participants can express views, whether or not implored, and can take initiatives of some sorts

vi. Interactive (empowering) participation: Participants have speech and their opinions can influence in the group's decisions

Accomplishing successful participation should ensure a move from the lower level of nominal participation to the more elevated levels of interactive participation, with levels being categorized here not by how a gathering is started but rather by the degree of individuals' vibrancy (Agarwal, 2001). Women's successful participation in Social audit basic leadership would require that they move toward becoming individuals from the gathering, as well as go to and talk in gatherings, and can (in any event a portion of the time) guarantee that decisions are considerate of them.

An important point to be noted in NGO model is that until Jan Sunwai (a meeting of the citizens of Gram Panchayat), the beneficiaries do not play any active role by adding to participation element other than being surveyed during stage of household visits. Their role of participation comes into existence only during Public Hearing and until then the social audit is run by the NGO and the MGNREGA officials. The mates who are both site supervisor as well as a semi-skilled worker in Sikkim is the only beneficiary who assists the SAU officials during house visit along with ward members and Gram Rozgar Sahayak.

All villagers are expected to participate in the Public Hearing but field visit in Sanghanath showed that mainly men from the household attended the event and women didn't attend much. But in Samlik Marchak GP, the number of women who attended the public hearing was in par with that of men. In Sikkim, the rule followed is that, for Jan Sunwai to begin at least 33\% of active workers in the GP should be present otherwise the block functionaries should conduct the public hearing again at their expense. As part of the this study, data from 30 GPs of four districts of Sikkim was collected from the four districts of Sikkim for two consecutive years 2016-17 and 2017-18 and the participation statistics over the years was analyzed. In the last two years, the participation has increased slightly from $34.25 \%$ to $35.96 \%$ as shown (Figure 2) and the standard deviation has also reduced slightly. But although the overall the participation seems to be greater than $33 \%$, in the year $2016,43 \%$ of the samples had less than $33 \%$ active household participation and it decreased to $30 \%$ of the samples violating the quorum in the subsequent year.

The gender wise participation data was also collected for these GPs and their trend of participation in terms of number was also analyzed as shown (Figure 3). In 2016-17, it was observed that men's participation (53.66\%) was slightly more than women $(46.34 \%)$ in terms of number and it is understandable owing to the fact that average women person days in MGNREGA of Sikkim is about $48 \%$. But in 2017-18, the participation of men seems to have slightly increased (55.24\%) but the woman participation (44.76\%) seems to have slightly gone below the previous year for the sample chosen.

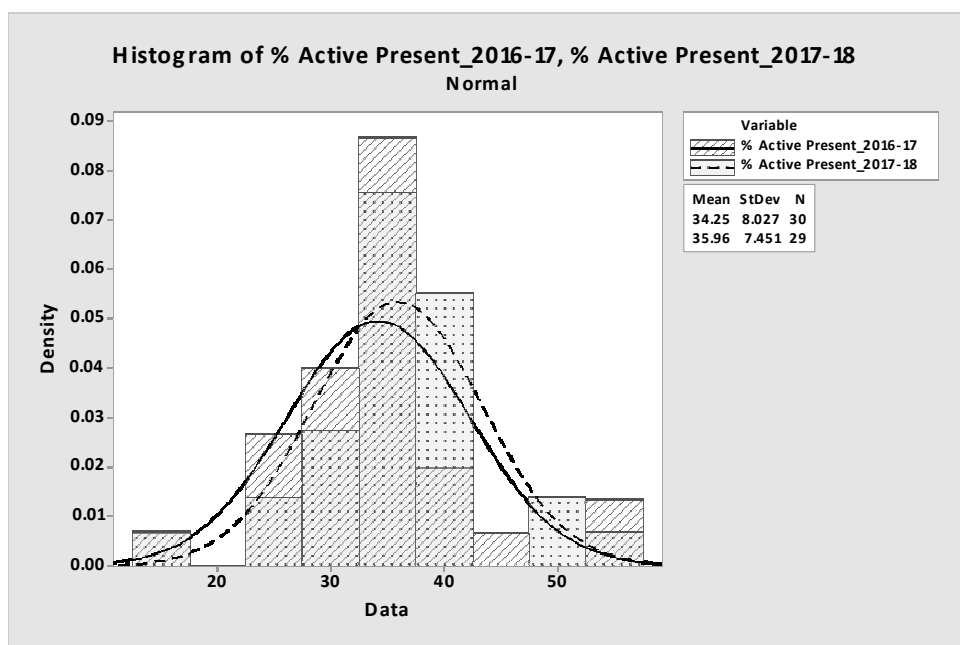

Figure 2. Sample Participation Statistics in 2016-17 \& 2017-18 

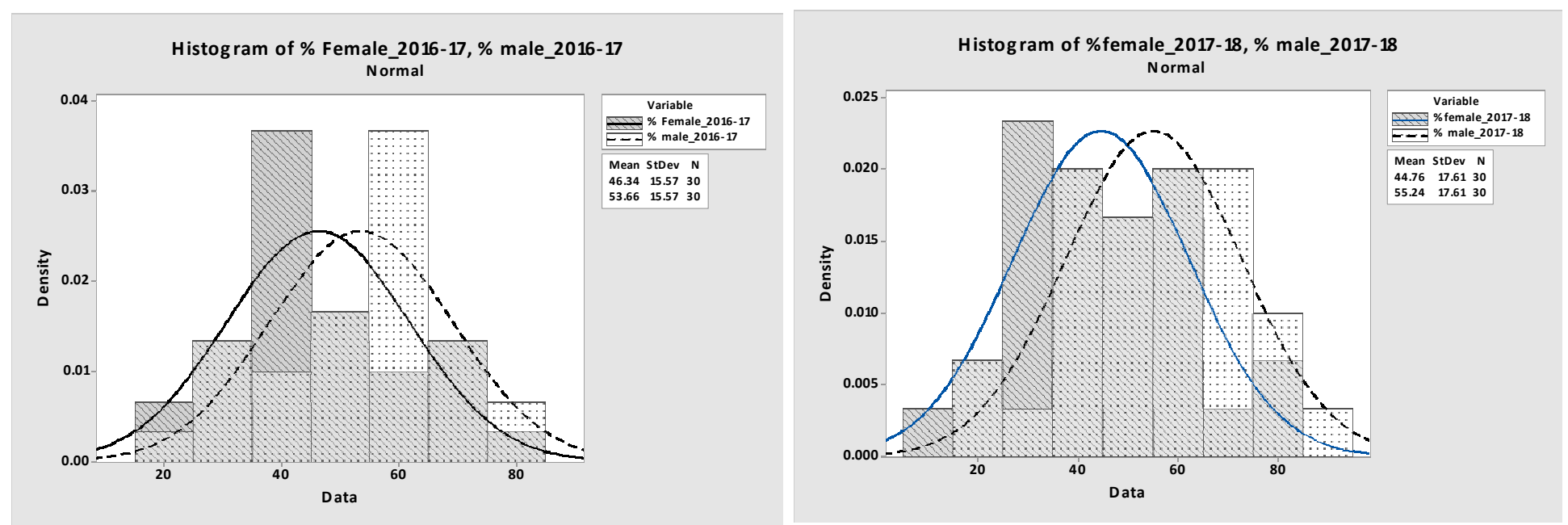

Figure 3. Sample Gender-wise Participation Statistics in 2016-17 \& 2017-18

In terms of absolute value, the average number of people attending a Public Hearing was about 113 people in the sample and there was also a case where 243 people attended a Public Hearing. From the field experience, it was also observed that the woman who participated in the Public Hearing was more vocal about their opinions during Public Hearing. The Public Hearing in Samlik Marchak was headed by woman political leader very contrasting to the case of observation in Maharashtra, women were very vocal about their opinion all throughout the Public Hearing. So, during Public Hearing active participation was observed from both men and women while there was interactive participation from the side of semi-skilled workers.

\section{Accountability}

Accountability in a democratic government includes both answerability and enforceability. Answerability is the obligation of office bearers to give data and legitimization about their activities while enforceability is the likelihood of punishments or outcomes for neglecting to answer accountability guarantees (Goetz \& Jenkins 2004).

Currently, public hearing is again the instrument utilized to meet the element answerability in accountability. In the first four days of audit, the SAU analyses the documents and interacts with the people in the first four days of audit to understand the issues and classify them primarily into four categories: Financial misappropriation, Financial deviation, Procedural violation and Grievances. Financial misappropriation involves cases where payment is made to person who did not work, Bribes, Work Related issues, Material Procurement etc. The issues related to denial of entitlements, lack of transparency \& accountability from officials, Work Selection issues, Maintenance of Registers etc., comes in the category of process violation and this was the most common issue cropping up in the audits. Records not produced, work Selection and work execution issues comes in financial deviation which checks if there is a deviation in finance than the sanctioned amount. The grievances section includes the issues from the people which may be related to Job Card, Aadhar / Bank Account, Work site facilities, Wages related Injury / Death, Individual Assets related, complaint on specific individuals etc. All the identified issues are discussed openly in the public hearing in the presence of all the people present and they are also represented in charts. The officials are answerable to any questions raised by the beneficiaries during the time of public hearing.

The Action Taken report (ATR) is to be submitted by the authorities and it is supposed to be discussed in the next consecutive year. But in the GPs visited, the ATR was not submitted by the block functionaries to the GP and it couldn't be discussed. So if no follow up action is taken it takes away the role of enforceability in accountability through social audit. The details of number of issues resolved after the audit is given (Table 3, as compiled from VHA). It was observed that the percentage of issues 
being resolved has reduced especially for west and east district and it was noted earlier that the issues reported was also more in these districts.

Table 3. Number of Issues Resolved after Social Audit

\begin{tabular}{|r|l|r|r|r|r|}
\hline \multicolumn{1}{|c|}{ S.L No. } & \multicolumn{1}{|c|}{ District } & $\mathbf{2 0 1 3 - 1 4}$ & $\mathbf{2 0 1 4 - 1 5}$ & $\mathbf{2 0 1 5 - 1 6}$ & \multicolumn{1}{|c|}{$\mathbf{2 0 1 6 - 1 7}$} \\
\hline 1 & North District & $39 \%$ & $48 \%$ & $44 \%$ & $56 \%$ \\
\hline 2 & East District & $67 \%$ & $63 \%$ & $53 \%$ & $14 \%$ \\
\hline 3 & South District & $96 \%$ & $90 \%$ & $86 \%$ & $59 \%$ \\
\hline 4 & West District & $79 \%$ & $76 \%$ & $47 \%$ & $16 \%$ \\
\hline Total & & $63 \%$ & $71 \%$ & $55 \%$ & $28 \%$ \\
\hline
\end{tabular}

Another big issue in MGNREGA is the case where beneficiaries do not use the assets constructed for the right purpose. For example, there were cases in the village where the beneficiary was using the cowshed for storage purposes instead of its actual purpose. The social audit teams also take note of these type of cases, interacts with the beneficiary and he/she is answerable in the public hearing to the other beneficiaries as to why he is not utilizing the assets for its actual cause. This type of internal answerability is also a good lesson from the NGO model of audit.

The element of enforceability is the tricky part and Social Audit agency being a facilitator and not implementer often have limitations in ensuring it. After the audit report is submitted, the role of enforceability still lies in the hands of the implementing institution by taking actions. So, the SAU may follow the method of collecting strong evidences to back up their review report submitting to the implementing department of MGNREGA. Whenever any issue is found out, photographs of the documents and testimonies are taken in writing from the concerned officials. They also take photographs and videos of the assets, testimonies, statements in the public hearing etc., to further back their evidences.

\section{Challenges of Social Audit: Field level}

The various challenges observed on field is discussed in detail in this section. The main issues are geographical challenges, errors in sampling, limiting works to checks and balances, weak follow-up and decision making, time constraints etc., and these are discussed below.

Firstly, Geographical terrain of the hilly state poses serious challenge to the social audit personnel in effectively carrying out their work in Sikkim. It is not practically possible for the social audit personnel to climb mountains and survey houses where vehicles are non-approachable within the limitations of time which is hardly 5 days in a GP. During the field visit and Non-participant observation, it was evident that not more than ten households can be covered in a day in such a difficult terrain where people are scattered. So often it is not possible to do regular inspections in areas because of the challenge of mobility. In many cases, if the house of the beneficiary is away from the main road and the social audit team would have to invest extra time just to visit that house and they are sometimes forced to end up surveying only houses close to the road side. But still we could see the team working hard to complete most of the ongoing and completed works for inspection. The geographical remoteness of people is also a reason that prevents them from attending social audit.

During official social audit of MGNREGA, most of the time the samples tend to be taken from houses that are close to the road alone because of the lack of time and difficulty in climbing. Owing to the difficulty in transportation, the MGNREGA officials also often do not keep a close check on the works far away from roadside and the quality of work may be tampered as a result of this problem. During the stay, it was found that the supervisors from the lower region of the ward was unwilling to visit the upper region of the mountain as it takes a journey of two hours back and forth and inspection was merely done by mobile phone without actual visit. This is typically a case where the street level bureaucrats are shifting towards screen level bureaucrats (Carausan, 2015). So is the case of monitoring 
as we observed with the Gram Rozgar Sahayak (GRS) and with the Junior Engineer (JE). But these areas which actually require more accountability to bring out their disadvantages when further disregarded by the social audit personnel due to lack of time and this create the doubts on efficiency of social audit as a TAP tool on field.

Secondly, the social audit reports are often limited to checks and balances based on the available format and sometimes there might be unwillingness among the personnel also to go beyond the realms of normal procedures. If Social audit is limited to checks and balances, the real purpose of transparency and accountability cannot be achieved through it. And involvement of NGO's having no relation to the beneficiaries coupled with time constraints, the level of commitment often gets reduce to task completion unless they have sincere motivation towards their work.

The third challenge is with respect to weak follow-up and decision making. SAU is merely a facilitating body and they aren't quite responsible for the final decisions according to the present structure of social audit observed in states. The offenders also learn to manipulate a new system while discovering other avenues through the institution of monitoring (Olken, 2009) (Afridi \& Iversen, 2013). Also, the action is taken by the implementing organization and the social audit team has no power in this other than reporting and evidence collection.

Fourthly, the SAU team is many times forced to be dependent on the MGNREGA officials to meet their requirements. According to the guidelines of the central government, the state governments are to set up a Social Audit Unit (SAU) that is independent from the executing authorities. But in order to operate on ground, the Social Audit Unit personnel are very much dependent on the MGNREGA officials as they are not familiar with the place of audit. We observed that the Gram Rozgar Sahayak (GRS), the MGNREGA mates and the Junior Engineer also travelled with the group of social auditors in their vehicle and the sample households were chosen under their guidance. In our visit there was an incident where a beneficiary shouted at the supervisor for not bringing the team to her house and she made accusations against the person. This again questions the real independence of the Social Audit Unit as an entity because there are practical difficulties to remain independent from the implementing agency in order to audit the scheme. In this case, instead of the supervisor, if it was a group of beneficiaries who were guiding the SAU personnel, then the audit team may have got a better perspective of the situation.

Fifthly, the team also faces difficulty in identifying problems in a short span of few days. Some of the corruption stages like labour related irregularities comprise of non- and delayed wage payment and a failure to provide work are ETD (easy to detect) while labour related irregularities comprise of benami and bribes are HTD (hard to detect). ETD related irregularities relates to 'ghost' or non-existent project. HTD material related irregularities comprise sub-standard material quality, material bribes and non-availability of material records (Afridi \& Iversen, 2014). Also, during the field stay with the villagers, we could observe more crude realities where materials were being hoarded with the knowledge of officials but all these abnormalities are difficult to be identified by an external agency unless people themselves are vocal about issues.

\section{Discussion}

Despite the various challenges discussed above, Sikkim has gone way ahead of other states in trying to overcome it. Some of the strikingly positive elements of NGO model in comparison to the society model are listed below and they would act as good lessons for other states for improvement. The Sikkim model follows a system of meticulous documentation and all the reporting formats are clearly laid out. So anyone joining the team can easily complete the verifications in line with the reporting formats. They were not just dependent on the downloaded MIS report of social audit sections from server but they had their own system suited to their purpose. Another highlight of the Sikkim model is good communication and awareness. In order to ensure good transparency, the message should be conveyed to the people in a way that it is understandable to them. So 'text' may not be the best suited way of communication in a village where there are illiterate people partaking in the scheme. Hence, Sikkim model also effectively utilizes cartoons and other pictorial representations to effectively convey the information to the public. 
In addition to it, announcements are also made on the microphone, to inform the people about public hearing. Even during the public hearing, the information is neatly depicted on charts for the people.

These type of Public Rural Appraisal activities are also required to ensure good involvement of people in social audit. One important point noted is that the delivery of possible multimedia communication was employed with due importance to culturally acceptable mode of communication. In our field visit we saw that announcements were not made on a particular day through microphone as a death had occurred that day in the village. It is really appreciable to see such respect for the traditions of the village from the social audit team while delivering their duties. The team by themselves being part of the same culture could also have been a reason for deepened understanding of the cultural setting. The auditors also question and checks the awareness of beneficiaries of their rights in MGNREGA. This type of approach in creating awareness through audit helps the beneficiaries as well to make better claims of their rights in future.

\section{Conclusion}

The needs and challenges in different states of India are different and hence a model working in one state may not be the best solution in another state although insights can be taken for improvement. In Andhra Pradesh, the society model is running effectively but it may not be suited to hilly state like Sikkim owing to different challenges in geography, density of population, educational opportunities etc.

The NGO model of social audit in Sikkim was analysed with the framework of transparency, accountability and participation and the observations seems to be largely successful with certain challenges at the micro-level. The main challenges include geography, errors in sampling, weak follow up, dependency on MGNREGA for choice of houses during visit, officials and the difficulty to identify problems. As a state social audit unit, the state is trying its own ways to overcome some of these challenges using meticulous documentation, team work and strong evidence collection. They also use good communication and awareness methods like cartoons and other pictorial representations to effectively convey the information the public. The NGO model of Sikkim seems to be good model for conducting social although there are windows of improvement to better the system.

Most importantly, the process of social audits clearly had a momentous impact on the citizens who were part of this process. The citizen's awareness of the government programme and their rights enhances and this has a long term positive impact on the delivery of the government programmes. Social Audits could therefore emerge as a catalyst in the process of citizen empowerment.

\section{References}

Aakella, Karuna Vakati and Soumya Kidambi. 2007. "Social Audits in Andhra Pradesh:A Process in Evolution." Economic and Political Weekly, Vol. 42. Issue No. 47

Afridi, F., \& Iversen, V. 2013: "Discussion Papers in Economics Social audits and MGNREGA Delivery: Lessons from Andhra Pradesh.” Indian Statistical Institute, Delhi Economics and Planning Unit 7, S. J. S. Sansanwal Marg, New Delhi 110016, India.

Afridi, F., \& Iversen, V. 2014: "Social audits and MGNREGA delivery: Lessons from Andhra Pradesh." Indian Statistical Institute and IZA. University of Manchester.

Agarwal, B. 2001. Participatory Exclusions, Community Forestry, and Gender: An Analysis for South Asia and a Conceptual Framework. World Development, 29(10), 1623-1648. Retrieved from www.elsevier.com/locate/worlddev

Aiyer Yamini and Bala Posani. 2009. "State of Accountability: Evolution, Practice and Emerging Questions in Public Accountability in India." AI Working Paper No. 2, May 2009. Accountability Initiative, Centre for Policy Research.

Aiyer Yamini and Salimah Samji. 2009. "Transparency and Accountability in NREGA: A Case Study of Andhra Pradesh.” New Delhi: Accountability Initiative, Centre for Policy Research.

CAG. 2016. Report issued by Comptroller and Auditor General of India, Union Government (Civil). Report no. 8 of 2016. Government of India. Accessed March 18, 2019. Available at https://cag.gov.in/sites/default/files/audit_report_files/Union_Civil_MGNREG_SOCIAL_Audit_Report_8_2016 .pdf.

Carausan, M. V. 2015: "Street-Level Bureaucrats: Theoretical Framework.” Discourse as a form of multiculturalism in literature and communication, ARHIPELAG XXI PRESS, TÎRGU MUREŞ, 2015. Available at http://www.upm.ro/ldmd/LDMD-03/Ssc/Ssc 03 50.pdf. 
Chandoke N. 2007. "Engaging with Civil Society: The democratic Perspective." Non-governmental Public Action Program, Center for Civil Society, London School of Economics and Political Science

Deshingar, P. and Johnson. 2003. "State Transfers to the Poor and Back: the Case of the Food for Work Program in Andhra Pradesh." Working Paper 222, Overseas Development Institute, www.odi.org.uk

Goetz, A.M and Jenkins J. 1999. "Accounts and Accountability: Theoretical Implications of the Right to Information Movement in India." Third World Quarterly, Vol. 20, No. 3 (1999).

Goetz, A. M., \& Jenkins, R. 2004: "Reinventing Accountability: Making Democracy Work for Human Development." Palgrave Macmillan UK, Available at https://books.google.co.in/books?id=yblmQgAACAAJ

Harrison, T. M., \& Sayogo, D. S. 2014.: "Transparency, participation, and accountability practices in open government: A comparative study." Government Information Quarterly 31(October): 513-525. Available at https://doi.org/10.1016/j.giq.2014.08.002.

Kalathil, S. 2016 . "Transparency, Accountability and Technology. Plan International USA. Retrieved from https://www.planusa.org/docs/ict-accountability-2015.pdf.

MoRD. 2013. MGNREGA Operational Guidelines, Ministry of Rural Development, Government of India.

Molinas, J. 1998. "The impact of inequality, gender, external assistance and social capital on local-level cooperation." World Development 26(3): 413-431. Available at https://doi.org/10.1016/S0305-750X(97)10066-3.

Olken, B. A. 2009: “Corruption perceptions vs. corruption reality." Journal of Public Economics 93(7-8): 950-964. Available at https://doi.org/10.1016/j.jpubeco.2009.03.001.

Tambe, S., Subba, A. B., Basi, J., Pradhan, S., \& Rai, B. B. 2016: "Measuring the effectiveness of social audits: experiences from Sikkim, India." Development in Practice 26(2): 184-192. Available at https://doi.org/10.1080/09614524.2016.1136268.

Thampi, Gopakumar K. 2005. "Can Public Feedback Enhance PublicAccountability? Experiences with Citizen Report Cards." Paper presented at the First International Forum on Citizen-Driven Evaluation of Public Services, Beijing, September 29, 2005.

The Centre for Good Governance. 2005. "Social Audit: A Toolkit A Guide for Performance Improvement and Outcome Measurement." Center for Good governance, Government of Andhra Pradesh.

Vij, N. 2011. “Collaborative Governance: Analysing Social Audits in MGNREGA in India.” IDS Bulletin 42(6): $28-34$. Available at https://doi.org/10.1111/j.1759-5436.2011.00269.x.

White, S. C. 1996. "Depoliticising development: The uses and abuses of participation.” Development in Practice 6(1)S, 6-15. Available at https://doi.org/10.1080/0961452961000157564. 